\title{
Evaluation of Overnight Orthokeratology For Correction of Myopia
}

\author{
Shrikant Waikar ${ }^{1}$, Ashish Saksena ${ }^{2}$ \\ ${ }^{I}$ Professor Ophthalmology, And Anterior Segment Microsurgeon, Command Hospital Chandimandir, India \\ ${ }^{2}$ Consultant Ophthalmology, Noida, India
}

\begin{abstract}
:
Background: Overnight orthokeratology is a technique for temporary reduction of myopia by reshaping the cornea with specially designed reverse geometry gas permeable orthokeratology lenses. Effect of overnight orthokeratology for correction of myopia was evaluated in 40 eyes of 20 patients of myopia with or without astigmatism.

Methods: 5 curve orthokeratology reverse geometry corneal reshaping lens was used. Pretreatment and posttreament unaided visual acuity, objective and subjective refraction, slit lamp examination and corneal topography findings were recorded. Orthokeratology lens was selected based on flat $k$ on corneal topography. Ideal fitting was confirmed and final lens prescribed. The orthokeratology lens was worn overnight from $2200 \mathrm{~h}$ to $0600 \mathrm{~h}$ next morning for a period of eight hours and repeat evaluation was done after removal of lens.

Results : Myopia correction of atleast $75 \%$ was achieved by overnight Orthokeratology after one night of lens wear. 22 eyes with myopia (Spherical equivalent) less than -2.00 D achieved unaided Snellens correction of 6/6, out of twelve eyes with myopia between $-2.00 \mathrm{D}$ to $-4.00 \mathrm{D}$ eight eyes achieved vision of $6 / 6$ and four achieved vision of 6/9. Six eyes with myopia between $-5.00 \mathrm{D}$ to $-5.50 \mathrm{D}$ achieved a vision of 6/18. Central corneal punctate staining was the only side effect seen in two eyes which could be controlled with artificial tears.

Conclusion: Orthokeratology is a safe, noninvasive, reversible technique highly effective for correction of myopia.
\end{abstract}

Keywords: Myopia,Orthokeratology, Overenight.

\section{Introduction}

Myopia or shortsightedness has been known to mankind since ages. Various methods have been tried over the years for correction of myopia besides spectacles and conventional contact lens. These include irreversible surgical and laser procedures such as radial keratotomy, photo refractive keratectomy and laser assisted stromal in situ keratomileusis (LASIK) Recent advances in lens designs and material and approval of overnight contact lens wear by Food and Drug administration (FDA) has led to a resurgence of interest in orthokeratology which was first introduced in 1960.

Overnight orthokeratology is the temporary reduction of myopia achieved by reshaping the cornea with specially designed reverse geometry gas permeable orthokeratology shaping lenses worn during sleep.

The early lenses were designed from poly methyl methacrylate (PMMA) and were flat fitting with frequent decentration leading to significant with the rule corneal astigmatism [1,2]. These lenses were not suitable for overnight wear.

Overnight orthokeratology utilizes reverse geometry lens designs made of high oxygen transmission [Dk] material. These can be worn overnight and do not cause induced with the rule astigmatism and result in corneal sphericalisation [3-6]. Initial attempts in orthokeratology required a series of lenses each lens flattening the cornea a small amount until the desired results were attained. This took months to years to accomplish. The advent of space-age oxygen polymers, computer assisted lathes and technological advancements in corneal measuring and mapping has made it possible to reverse myopia in a matter of hours. Hence modern orthokeratology is also called accelerated orthokeratology.

Modern orthokeratology reverse geometry lenses are fitted with a base curve flatter than the central corneal curvature. This exerts a positive pressure as a result of which the central corneal epithelium is thinned out [7] the sagittal corneal height is decreased which shortens the length of the eye reducing the corneal power resulting in correction of myopia. An evaluation of overnight orthokeratology for correction of myopia has been carried out in this study. 


\section{Methods}

40 eyes of 20 patients of Myopia with or without astigmatism underwent overnight Orthokeratology using 5 curve reverse geometry corneal reshaping lens.

\section{Inclusion Criteria}

- Age group between 8 yrs to 35 yrs.

- Myopia (Spherical equivalent) up to -6.00 D.

\section{Exclusion Criteria}

- Corneal dystrophies.

- Dry eyes.

- Any other associated ocular disease.

- Any ocular Surgery in the past.

- Any refractive procedure in the past.

- Any ocular surface pathology.

Pretreatment and post treatment unaided visual acuity, objective and subjective refraction, slit lamp examination and corneal topography findings were recorded. Orthokeratology lens was selected based on flat keratometry reading $(\mathrm{K})$ on corneal topography. The trial lens with nearest K reading was selected from the trial kit and placed on patient's eye. Ideal fitting was confirmed using fluorescein staining. After initial one hour trial fitting final lens was prescribed. The orthokeratology lens was worn overnight from $2200 \mathrm{~h}$ to $0600 \mathrm{~h}$ next morning for a period of 8 hours and repeat evaluation was done after removal of lens. Findings were recorded and analysed.

\section{Results}

40 eyes of 20 patients were included in this study. The youngest patient was 8 year old and the oldest was 35 years of age. There were 6 patients in 8 to 12 years age group, 8 between 13 to 17 years and 6 were 18 years and above [Table-1].

table-1 Age distribution

\begin{tabular}{|c|c|c|c|c|c|c|}
\hline S/no & Age group & Number & Males & $\%$ & Females & $\%$ \\
\hline 1. & $8-12$ & 6 & 2 & 33.3 & 4 & 66.6 \\
\hline 2. & $13-17$ & 8 & 2 & 25 & 6 & 75 \\
\hline 3. & $>18$ Yrs & 6 & 1 & 16.6 & 5 & 83.3 \\
\hline & Total & 20 & 5 & 25 & 15 & 75 \\
\hline
\end{tabular}

There were 5 males and 15 females . [Table-2].

Table-2 Sex distribution

\begin{tabular}{|c|c|c|}
\hline S/no & Sex & Number \\
\hline 1. & Male & 5 \\
\hline 2. & Females & 15 \\
\hline
\end{tabular}

14 eyes had simple myopia and 26 had compound myopic astigmatism. Six eyes had against the rule astigmatism of $-0.50 \mathrm{D}$ to $-1.00 \mathrm{D}$. 18 eyes had with the rule astigmatism ranging between $-0.50 \mathrm{D}$ to $-1.00 \mathrm{D}$. Two eyes had a with the rule astigmatism of $-2.00 \mathrm{D}$ and $-3.00 \mathrm{D}$ respectively. The spherical equivalent refraction was calculated and the effect of overnight orthokeratology with 5 curve reverse geometry corneal reshaping lens was assessed. 22 eyes with myopia (spherical equivalent) of up to $-2.00 \mathrm{D}$ with visual acuity varying between $6 / 12$ to $6 / 18$ achieved unaided vision of $6 / 6$ after removal of the 5 curve reverse geometry orthokeratology lens applied over the eye for one night. These eyes had a complete correction of myopia. Out of 12 eyes with myopia (spherical equivalent) between -2.00 to $-4.00 \mathrm{D}$ two eyes had a prelens unaided vision of $6 / 18$, six had vision of $6 / 24$ and four had a vision of 6/36. After overnight application of orthokeratology lens eight eyes with vision upto $6 / 24$ achieved unaided vision of $6 / 6$ and four achieved 6/9. Six eyes had myopia (spherical equivalent) of $-5.00 \mathrm{D}$ to $-5.50 \mathrm{D}$. They had unaided vision of $3 / 60$ and improved to $6 / 18$ after overnight application of the orthokeratology lens. 30 out of 40 eyes (75\%) achieved a vision of 6/6 There was an improvement of at least two lines on Snellens chart in every case. Some eyes even showed improvement of 4 Snellens line with just one night of Orthokeratology lens application [Table-3]. 
Table-3 Improvement in visual acuity after overnight orthokeratology

\begin{tabular}{|c|c|c|c|}
\hline S/No & Visual acuity & Pre orthokeratology visual acuity & Post orthokeratology visual acuity \\
\hline 1. & $6 / 6$ & 0 & 30 \\
\hline 2. & $6 / 9$ & 0 & 4 \\
\hline 3. & $6 / 12$ & 10 & 0 \\
\hline 4. & $6 / 18$ & 14 & 6 \\
\hline 5. & $6 / 24$ & 6 & 0 \\
\hline 6. & $6 / 36$ & 4 & 0 \\
\hline 7. & $6 / 60$ & 0 & 0 \\
\hline 8. & $3 / 60$ & 6 & 0 \\
\hline
\end{tabular}

Eyes with myopia (spherical equivalent) upto -2.00 D achieved full correction where as eyes with more than 2.00 D myopia achieved atleast $75 \%$ correction [Table-4].

Table-4 Degree of myopia vs post orthokeratology visual out come

\begin{tabular}{|c|c|c|c|c|c|}
\hline S/No & $\begin{array}{l}\text { Degree of myopia } \\
\text { (spherical equivalent) }\end{array}$ & $\begin{array}{l}\text { No of } \\
\text { eyes }\end{array}$ & $\begin{array}{l}\text { Preorthokeratolog } \\
\text { y } \\
\text { Visual acuity }\end{array}$ & $\begin{array}{l}\text { Postorthokeratology } \\
\text { Visual acuity }\end{array}$ & $\begin{array}{l}\text { No of snellens line } \\
\text { improved }\end{array}$ \\
\hline 1. & $<-2.00 \mathrm{D}$ & 10 & $6 / 12$ & $6 / 6$ & 2 \\
\hline 2. & $-2.25 \mathrm{D}$ to & 2 & $6 / 18$ & $6 / 6$ & 3 \\
& $-4.00 \mathrm{D}$ & 6 & $6 / 18$ & $6 / 6$ & 4 \\
\hline 3. & $-4.25 \mathrm{D}$ to & 6 & $6 / 36$ & $6 / 9$ & 4 \\
\hline
\end{tabular}

Statistical Analysis paired $\mathrm{t}$ test $\mathrm{P}<0.001$ highly significant.

Statistical analysis showed that the correction of myopia as reflected in improvement of visual acuity was statistically highly significant at $\mathrm{p}<0.001$ [Table-4].

Table-5 Correction of myopia after overnight orthokeratology

All eyes except four were within the recommended range of $-0.50 \mathrm{D}$ for against the rule astigmatism and $-1.50 \mathrm{D}$ for with the rule astigmatism but all showed significant improvement in visual acuity. Even the two eyes of one patient who had with the rule astigmatism of $-2.00 \mathrm{D}$ and $-3.00 \mathrm{D}$ also showed significant improvement in visual acuity. The only side effect observed was punctate staining of central cornea in 2 eyes which improved with application of ocular lubricants.

\begin{tabular}{|c|c|c|c|c|}
\hline S/No & Myopia correction & $\begin{array}{c}\text { Pretreatment myopia } \\
0.00 \text { to }-2.00 \mathrm{~d}\end{array}$ & $\begin{array}{c}\text { Pretreatment myopia } \\
-2.25 \text { to }-4.00 \mathrm{~d}\end{array}$ & $\begin{array}{c}\text { Pretreatment myopia } \\
-4.25 \text { to }-6.00 \mathrm{~d}\end{array}$ \\
\hline 1. & $>-1.50$ To- 2.00 & 22 & 2 & - \\
\hline 2. & $>-2.00$ To-2.50 & - & 6 & - \\
\hline 3. & $>-2.50$ To-3.00 & - & 4 & - \\
\hline 4. & $>-3.00$ To-3.50 & - & - & - \\
\hline 5. & $>-3.50$ To-4.00 & - & - & 6 \\
\hline 6. & $>-4.00$ To-4.50 & - & 12 & 6 \\
\hline & Total & 22 & & - \\
\hline
\end{tabular}

\section{Discussion}

Various options are available for management of myopia. Some are noninvasive and safe such as simple spectacles or conventional contact lens. Other are invasive such as excimer laser photo refractive keratectomy or laser combined with surgery such as LASIK which permanently alter the structure of cornea. Certain intra ocular surgical procedures such as implantable contact lens (ICL), phakic intraocular lens or even clear lens extraction have been advocated by some practitioners which have obvious risks being surgical procedures. Overnight orthokeratology a much less known technique is another noninvasive procedure which can reduce or eliminate myopia in both adults and children using specially designed reverse geometry corneal reshaping lens by redistributing the corneal epithelium leading to flattening of central cornea. Availability of high oxygen transmission ( Dk) lens materials has enabled safe overnight wear. This has led to a resurgence of interest in orthokeratology. We evaluated the efficacy of overnight orthokeratology with 5 curve reverse geometry corneal reshaping lens for correction of myopia over a period of one night. All eyes with myopia less than -2.00 D achieved full correction of 6/6 over one night indicating a complete correction of myopic visual loss. Other eyes with myopia more than $-2.00 \mathrm{D}$ also showed correction of over 2 Snellens line and upto 4 
Snellens line in some cases. The visual recovery after application of orthokeratology lens was statistically highly significant. Similar result has been reported in various studies in different ethnic communities [8-11]. There were 6 patients in 8-12 year age group and 8 between 13 to 17 years. A good orthokeratology response was observed in this young age group. Evidence in literature also points to the fact that overnight orthokeratology is efficacious and safe for young myopic patients $[12,13]$. All eyes with compound myopic astigmatism also showed significant improvement in visual acuity after overnight orthokeratology lens application.

Certain adverse effects have been reported in literature. Corneal staining has been most commonly observed which improved with ocular lubricants [14]. Central punctate staining was observed in 2 out of 40 eyes which also improved with ocular lubricants. This can be avoided with due care while achieving the ideal lens fit. Microbial keratitis has been reported $[15,16]$ but it is usually a consequence of inappropriate lens care routine. No case of microbial keratitis was encountered in this study. No major adverse effects were noticed in this study because of short duration of lens wear. Long term follow-up is recommended which will assess the safety of these lenses over a long term.

Overnight orthokeratology with 5 curve reverse geometry corneal reshaping lens has been found to correct the myopia rapidly and it dramatically improves the unaided visual acuity with just one night of lens application $[9,17,18]$. Modern orthokeratology gives predictable results. It is highly useful for patients who want to be spectacle free to participate in various sports particularly contact sports like boxing, wrestling, those who work in dusty areas and cannot wear conventional contact lens. It is particularly useful for certain professions like police, firemen and sports person. It is non invasive and reversible. It can be used in children unlike LASIK. The effect of orthokeratology in slowing the progression of myopia in children has also been reported [19].

\section{Conclusion}

Orthokeratology is a safe, noninvasive, reversible technique highly effective for correction of myopia. It is a viable option for correction and treatment of myopia in children as well as adults and being reversible is superior to other invasive and irreversible laser and surgical techniques. It is particularly useful in children as the option of laser correction is not there. This study was just an initial evaluation of overnight orthokeratology for correction of myopia. Long term followup and side effects over long term were beyond the scope of this study. A prospective study to evaluate the safety of this technique over a long term is recommended.

\section{References}

[1]. Kerns RL. Research in Orthokeratology. Part VIII: results, conclusions and discussion of techniques. J Am Optom Assoc 1978;49:308-14.

[2]. Binder PS, May CH, Grant SC. An evaluation of Orthokeratology. Ophthalmology 1980;87:729-44.

[3]. Nichols JJ,Marsich MM,Nguyen M, et al.Overnight Orthokeratology optom Vis Sci 2000;77:252-9.

[4]. Swarbrick HA, Alharbi A. Overnight Orthokeratology induces central corneal epithelial thinning.Invest Ophthalmol Vis Sci 2001;42:S597.

[5]. Mountford J. An analysis of the change in corneal shape and refractive error induced by accelerated orthokeratology. ICLC 1997;24:128-44

[6]. Lui W-O, Edwards MH.Orthokeratology in low myopia. Part 1: efficacy and predictability . Cont Lens Anterior Eye 2000;23:77-89.

[7]. Wlodyga RJ,Bryla C.Corneal molding: the easy way. Contact Lens Spectrum 1989;4:58-65.

[8]. Johnson KL, Carney LG, Mountford JA, Collins MJ, Cluff5, Collins PK. Visual performance after overnight orthokeratology. Cont Lens Anterior Eye. 2007 Mar;30(I):29-36. Epub 2007 Jan 9.

[9]. Soni PS,Nguyen TT;XO Overnight Orthokeratology Study Group. Overnight Orthokeratology experience with XO material. Eye Contact Lens. 2006 Jan;32(I):39-45.

[10]. Cheung SW,Cho P, Chui WS, Woo GC. Refractive error and visual acuity changes in Orthokeratology patients. Optom Vis Sci. 2007 May;84(5):410-6.

[11]. Chan B, Cho P, Cheung SW Orthokeratology practice in children in a university clinic in Hong Kong. Clin Exp Optom. 2008 Sep;91(5)453-60. Epub 2008 Mar 18.

[12]. Walline JJ,Rah MJ, Jones LA The children's Overnight Orthokeratology Investigation (COOKI) pilot study. Optom Vis Sci.2004 Jun;81(6):407-13.

[13]. Rah MJ, Jackson JM, Jones LA, Marsdem HJ,Bailey MD, Barr JT Overnight Orthokeratology: preliminary results of the Lenses and Overnight Orthokeratology (LOOK) study. Optom Vis Sc. 2002 Sep;79(9):598-605.

[14]. Chan B,Cho P, Cheung SW. Orthokeratology practice in children in a university clinic in Hong Kong. Clin Exp Optom. 2008 Sep;91(5):453-60. Epub 2008 Mar 18.

[15]. Watt KG,Swarbrick HA.Trends in Microbial keratitis associated with Orthokeratology. Eye Contact Lens. 2007 Nov;33(6pt 2):3737; discussion 382.

[16]. Shehadeh-Mashaour R, Segev F, Barequet IS, Ton Y, Garzozi HJ.Orthokeratology associated microbial keratitis. Eur J Opthalmol.2009 Jan-Feb;19(I):133-6.

[17]. Soni PS, Nguyen TT, Bonanno JA. Overnight orthokeratology: Visual and corneal changes, Eye contact lens 2003:29:137-145.

[18]. Soni PS, Nguyen TT, Bonanno JA. Overnight orthokeratology: Refractive and corneal recovery following discontinuation of reverse geometry lenses. Eye contact lens 2004:30:254-262.

[19]. Cho P, Cheung SW, Edwards M. The longitudinal orthokeratology research in children (LORIC) in Hong Kong. A Pilot study on refractive changes and myopic control. Curr Eye Res 2005:30:71-80.

[20]. Li SM, Kang MT, Wu SS, Liu LR, Li H, Chen Z, Wang N. Efficacy, Safety and Acceptability of Orthokeratology on Slowing Axial Elongation in Myopic Children by Meta-Analysis. Curr Eye Res. 2015 Aug 3:1-9. [Epub ahead of print] 
[21]. Daizong Wen, Jinhai Huang, Hao Chen, Fangjun Bao, Giacomo Savini, Antonio Calossi, Haisi Chen, Xuexi Li, and Qinmei Wang. Efficacy and Acceptability of Orthokeratology for Slowing Myopic Progression in Children: A Systematic Review and MetaAnalysis.J Ophthalmol. 2015; 2015: 360806 .

[22]. Published online 2015 Jun 11. doi: 10.1155/2015/360806 